\title{
Left ventricular gradients in hypertrophic cardiomyopathy
}

Sir,

Sugrue et al (1984;52:602-9) reported that their group of eight patients with hypertrophic cardiomyopathy and mean resting gradient of $42 \mathrm{~mm} \mathrm{Hg}$ did not show evidence of impedance to left ventricular emptying. This finding corroborates recent observations of systolic anterior motion of the mitral valve. At a gradient of $42 \mathrm{~mm} \mathrm{Hg}$ subaortic obstruction (as demonstrated by systolic anterior motion with septal contact) would not have occurred until $40 \%$ of the way through the systolic ejection period, by which time $80 \%$ of stroke volume would have already been ejected. ${ }^{1}$ The results of Sugrue et al cannot, however, be extrapolated to suggest that "a left ventricular gradient does not represent true obstruction" for two reasons. Firstly, left ventricular emptying must be interpreted in the light of the associated mitral regurgitation accompanying systolic anterior motion with septal contact. The left ventricle ejects rapidly in patients with hypertrophic cardiomyopathy, and any tendency to slow down this rapid ejection by the resulting subaortic obstruction from systolic anterior motion with septal contact may be counterbalanced by the accompanying mitral regurgitation, which will facilitate rapid emptying. ${ }^{2}$ Secondly, the size of the pressure gradient is crucial in the interpretation of studies of left ventricular emptying. Thus when the pressure gradient is as high as $140 \mathrm{~mm} \mathrm{Hg}$ systolic anterior motion with septal contact develops as early as $10 \%$ of the way through systole, and the resulting subaortic obstruction occurs when $93 \%$ of the stroke volume has still to be ejected. ${ }^{1}$ Just as systolic anterior motion is not an "all or none phenomenon" so the subaortic pressure gradient is not an "all or none phenomenon." Gradients such as those in the patients studied by Sugrue et al do not usually suggest important left venticular obstruction. Higher pressure gradients do suggest significant outflow obstruction as shown by prolonged ejection time, ${ }^{1}$ fall in ejection fraction with exercise, ${ }^{3}$ and amelioration of angina when the pressure gradient is relieved. ${ }^{4}$

Charles Pollick,

Division of Cardiology,

Toronto Western Hospital,

399 Bathurst Street,

Toronto,

Ontario, Canada.

\section{References}

1 Pollick C, Rakowski H, Wigle ED. Muscular subaortic stenosis: the quantitative relationship between systolic anterior motion and the pressure gradient. Circulation 1984;69:43-9.

2 Wigle ED, Adelman AG, Auger P, Marquis Y. Mitral regurgitation in muscular subaortic stenosis. Am f Cardiol 1969;24:698-706.

3 Pollick C, Bar-Shlomo B, McLaughlin PR, et al. Hypertrophic cardiomyopathy: ventricular function studied by radionuclide angiography [Abstract]. Circulation 1980;62(suppl III):302.

4 Pollick C. Muscular subaortic stenosis. Hemodynamic and clinical improvement after disopyramide. $N$ Engl $\mathcal{F}$ Med 1982;307:997-9.

This letter was shown to the authors, who reply as follows:

Sir,

Dr Pollick's comments on the influence of mitral regurgitation and of the importance of the magnitude of left ventricular gradients on left ventricular ejection are made from the perspective of his elegant work which demonstrates a strong positive correlation of the duration of systolic anterior motion, the left ventricular ejection time, and the magnitude of left ventricular gradient in patients with muscular subaortic stenosis. ${ }^{1}$ These patients are a subset of the spectrum of hypertrophic cardiomyopathy - namely, those with an idiopathic heart muscle disorder which is characterised by a hypertrophied and non-dilated left ventricle. $^{2}{ }^{3}$ In such patients left ventricular gradients may or may not be observed, and their presence is associated not only with systolic anterior motion but with other mechanisms that are not associated with mitral regurgitation.

As stated, the patients in our study did not have moderate or significant mitral regurgitation. In our large series of patients with hypertrophic cardiomyopathy $35 \%$ had a resting left ventricular gradient of between 30 and 120 (median 45) $\mathrm{mm} \mathrm{Hg}$ and patients with a gradient in excess of $80 \mathrm{~mm} \mathrm{Hg}$ were rare $(<10 \%)$. Our findings are relevant to the majority of patients with hypertrophic cardiomyopathy who have a resting left ventricular gradient. We have sub- 
sequently compared the proportion of stroke volume ejected during the various phases of systole in 11 patients with resting left ventricular gradients of 50 120 (median 80) $\mathrm{mm} \mathrm{Hg}$ and patients without resting or provocable gradients who were matched for age, sex, and ejection fraction. The initial third, the initial $50 \%$, and the initial $80 \%$ of systole were similar in those with and without left ventricular gradients. These findings support our conclusion that a left ventricular gradient does not represent true obstruction.

WJ McKenna, *

DD Sugrue, $\dagger$

*Cardiovascular Disease Unit,

Department of Medicine,

Royal Postgraduate Medical School,

London;

†Division of Cardiovascular Disease, Mayo Clinic,

Minnesota, USA.
References

1 Pollick C, Rakowski H, Wigle ED. Muscular subaortic stenosis: the quantitative relationship between systolic anterior motion and the pressure gradient. Circulation 1984;69:43-9.

2 Maron BJ, Epstein SE. Hypertrophic cardiomyopathy: recent observations regarding the specificity of three hallmarks of the disease: asymmetric septal hypertrophy, septal disorganization and systolic anterior motion of the anterior mitral leaflet. Am F Cardiol 1980;45:141-54.

3 Goodwin JF. The frontiers of cardiomyopathy. Br Heart f 1982;48:1-18.

\section{Notices}

\section{Cardiac Doppler}

An international congress on cardiac Doppler will be held in Pisa from 14 to 18 October 1985. Further details may be obtained from $\operatorname{Dr}$ Alessandro Distante, Istituto di Fisiologia Clinica, CNR, Università di Pisa, Via Savi 8, 1-567100 Pisa, Italy.

\section{British Cardiac Society}

The Autumn Meeting will be held at the Wembley Conference Centre, London, on 26 to 28 November 1985 , and the closing date for receipt of abstracts will be 1 August 1985.

The Annual General Meeting for 1986 will take place in York on 2 and 3 April 1986, and the closing date for receipt of abstracts will be 2 January 1986 .

\section{Correction}

In the paper by Fioretti et al (1985; 53: 248-52) on the "Limitations of a QRS scoring system to assess left ventricular function and prognosis at hospital discharge after myocardial infarction" the curves for ejection fraction and QRS score in Fig. 3 should have been represented by a continuous line (- ${ }^{-}$) and a broken line (- - ) respectively. 